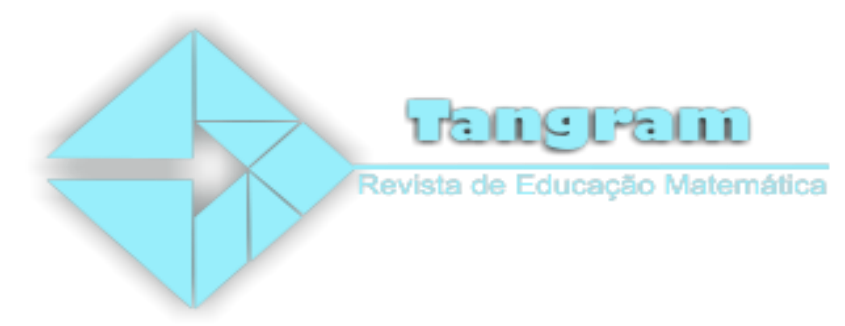

\title{
Música e Modelagem Matemática: representações de notas musicais por meio da função seno
}

\section{Music and Mathematical Modeling: representations of musical notes through the sine function}

\author{
Felipe Leite Pontes ${ }^{1}$ \\ Zulma Elizabete de Freitas Madruga ${ }^{2}$
}

\begin{abstract}
Resumo: Este artigo apresenta uma pesquisa que tem por objetivo construir um modelo, utilizando notas musicais, que possa ser aplicado no ensino de matemática. Para tanto, utiliza-se das etapas referentes ao processo de modelagem matemática para construção do referido modelo. Ao tocar um violão, foram feitas gravações de notas musicais em ambiente computacional - software, e posteriormente a análise da escala musical da nota Ré, a fim de perceber a relação de proporção entre elas a partir da frequência. A partir disso, foi realizada uma representação dessa mesma nota musical no software Geogebra, a qual originou em um gráfico representativo da função seno. A construção do modelo mostra relações podem ser exploradas em sala de aula, por meio da modelagem matemática, por exemplo. Atividades como estas, se aplicadas em sala de aula, podem facilitar a aprendizagem de Matemática, especificamente de funções trigonométricas - função seno.
\end{abstract}

Palavras-chave: Modelagem Matemática. Música. Função seno.

\begin{abstract}
This paper presents a research that aims to build a model using musical notes that can be applied in mathematics teaching. So, we use the steps related to the mathematical modelling process for the construction of said model. When playing a guitar, recordings of musical notes were made in a computational environment - software, and afterwards the analysis of the musical scale of the note Ré, in order to perceive the relation of proportion between them from the frequency. From this, a representation of this musical note was made in Geogebra software, which originated in a graph representing the sine function. The construction of the model shows relationships can be explored in the classroom, through mathematical modeling, for example. Activities like these, if applied in the classroom, can facilitate the learning of Mathematics, specifically trigonometric functions - sine function.
\end{abstract}

Keywords: Mathematical Modeling. Music. Sine functions.

\footnotetext{
${ }^{1}$ Licenciado em Matemática. Universidade Estadual de Santa Cruz - UESC. felipeleitepontes@ hotmail.com ${ }^{2}$ Doutora em Educação em Ciências e Matemática. Universidade Federal do Recôncavo da Bahia - UFRB. betemadruga@ufrb.edu.br
}

Tangram - Revista de Educação Matemática, Dourados - MS - v.2 n.4, pp. $79-95$ (2019) 


\section{Música e Modelagem Matemática: representações de notas musicais por meio da função seno}

\section{Introdução}

A música influencia consideravelmente a sociedade desde tempos remotos. Gardner (1994) afirma que ao longo dos séculos, várias foram as tentativas de associar Matemática e música. Segundo o autor, é possível encontrar pensamento matemático em meio a estruturas da música. Em sua teoria sobre inteligências múltiplas, Gardner $(1994,1995)$ aponta sete tipos básicos de inteligências, entre elas destaca-se a lógico-matemática e a musical. A inteligência lógico-matemática está associada à resolução de problemas e ao desenvolvimento de raciocínios dedutivos, esta inteligência desperta interesse por parte de epistemólogos e psicólogos. Já a inteligência musical é comumente considerada como “dom”, o qual a pessoa apresenta desde a infância. Conforme Gardner (1994, p.98): "No que tange à apreciação de estruturas musicais básicas e como elas podem ser repetidas, transformadas, embutidas ou permutadas entre si, encontra-se pensamento matemático em uma escala um tanto mais elevada".

Ainda de acordo com Gardner (1994, p. 98), "há elementos claramente musicais, quando não de 'alta matemática' na música: estes não deveriam ser minimizados. Para apreciar a função dos ritmos no trabalho musical o indivíduo deve ter alguma competência numérica básica”. Diversas pesquisas mostram a relação entre música e Matemática, entre elas, pode-se destacar as de Camargos (2010) e Grams (2014) que, além de relacionar Matemática e música, trazem a ideia dessas relações com a modelagem matemática. Modelagem "é o processo envolvido na elaboração de modelo de qualquer área do conhecimento" (Biembengut, 2014, p.21).

Dentre vários fatores que estreitam a relação entre Matemática e música, Abdounur (2003) afirma que a interação entre essas áreas se manifesta a partir da necessidade de equacionar e solucionar problemas de consonância, no sentido de buscar fundamentos científicos para justificar tais conceitos. E continua, ao afirmar que os conceitos que podem explicar consonância e dissonância estão relacionados a fatores sócio-culturais, assim como assuntos de Física e Matemática.

Os saberes matemáticos são essenciais para qualquer estudante da Educação Básica. No Ensino Médio, por exemplo, a maioria desses estudantes apresentam dificuldades em aprender conteúdos matemáticos com métodos convencionais, por meio de teoremas e lista

Tangram - Revista de Educação Matemática, Dourados - MS - v.2 n.4, pp. 79 - 95 (2019) 


\section{Música e Modelagem Matemática: representações de notas musicais por meio da função seno}

de exercícios. O ideal é fazer com que o estudante participe da situação, perceba ainda que o conhecimento que está sendo aprendido em sala de aula, faz parte de seu cotidiano.

A Lei $n^{\circ} 11.769^{3}$ estabelece a obrigatoriedade do ensino de Música nas escolas, alterando a Lei de Diretrizes e Bases - LDB no 9.394/96, (Brasil, 1996), a qual passou a vigorar acrescida do seguinte: “ $\S 6^{\circ}$ : A música deverá ser conteúdo obrigatório, mas não exclusivo, do componente curricular de que trata o $§ 2^{\circ}$ deste artigo" (Brasil, 2013, p. 31).

A Música, conforme prevê a Lei nº 11.769, é parte do programa da Educação Básica não somente na disciplina de Arte, a qual possui estreita vinculação, mas poderá ser utilizada como recurso didático em qualquer componente curricular, em todos os níveis de ensino. De acordo com Grams (2014, p. 21): “a integração da Música na escola faz sentido quando é parte de um currículo escolar no contexto interdisciplinar, em que subentendem-se disciplinas interligadas em função de metas comuns, sem limitar-se ao contexto de uma só disciplina”.

No que tange às tecnologias, a Base Nacional Comum Curricular - BNCC (BRASIL, 2018) sugere que os estudantes as utilizem desde os anos iniciais do Ensino Fundamental. No Ensino Médio, o foco deve ser a construção de uma visão integrada da Matemática, aplicada à realidade, deixando claras indicações para construção de modelos, além da utilização da tecnologia.

Nessa direção, e com o intuito de atender as orientações da BNCC e a Lei 11.769, buscaram-se relações entre a Matemática e a Música, por meio da elaboração de um modelo de função seno, que possa servir para uma futura utilização em sala de aula. Para isso, temse o objetivo construir um modelo, utilizando notas musicais, que possa ser aplicado no ensino de matemática. Após a elaboração e análise do modelo, buscam-se caminhos para aplicação no Ensino Médio.

\section{Pressupostos teóricos: Modelagem Matemática}

\footnotetext{
${ }^{3}$ Lei no 11.769 , de 18 de agosto de 2008. A qual altera a Lei no 9.394, de 20 de dezembro de 1996, Lei de Diretrizes e Bases da Educação, para dispor sobre a obrigatoriedade do ensino da música na educação básica. Disponível em: http://www.planalto.gov.br/ccivil_03/_ato2007-2010/2008/lei/111769.htm Acesso em 20 de julho de 2018.
}

Tangram - Revista de Educação Matemática, Dourados - MS - v.2 n.4, pp. 79 - 95 (2019) 


\section{Música e Modelagem Matemática: representações de notas musicais por meio da função seno}

O termo "Modelagem" está presente nas diversas áreas do conhecimento e das ciências, como por exemplo: na Biologia, na Moda, nas Artes: na Matemática, por sua vez, se apresenta da seguinte forma, afirma Biembengut (2016). "Modelagem (matemática) é um método para solucionar alguma situação-problema ou para compreender um fenômeno utilizando-se de alguma teoria (matemática)" (Biembengut, 2016, p. 104).

$\mathrm{Na}$ Matemática, a modelagem pode ser entendida como uma forma de traduzir o conhecimento matemático, visto que no ambiente escolar, este é apenas transmitido por meio de algoritmos, na maioria das vezes. Fato este que pode não ser bem recebido por parte dos estudantes.

De acordo com Bassanezi (2010) ao ser feita uma análise de uma situação real, cientificamente com propósito de substituir a versão ingênua da mesma por um ponto de vista crítico e mais abrangente, é essencial a elaboração de linguagem adequada que facilite e racionalize o pensamento. Neste contexto a modelagem se encaixa com a proposta de solucionar problemas relacionados ao cotidiano, comprometida não apenas com o conteúdo matemático a ser transmitido, mas também com as mais distintas situações da vivência do ser humano. A modelagem pode ser considerada como os procedimentos requeridos para a elaboração de um modelo (BIEMBENGUT, 2014). Segundo Bassanezi (2010), modelo matemático trata-se de "um conjunto de símbolos e relações matemáticas que representam de alguma forma o objeto estudado" (Bassanezi, 2010, p.20). Para Biembengut (2014, p. 21):

Modelagem é o processo envolvido na elaboração de modelo de qualquer área do conhecimento. Trata-se de um processo de pesquisa. A essência deste processo emerge da mente de uma pessoa quando alguma dúvida genuína ou circunstância instigam-na a encontrar uma melhor forma de alcançar uma solução, descobrir um meio de compreender, solucionar, alterar, ou ainda, criar ou aprimorar algo. E em especial, quando a pessoa tem uma percepção que instiga a sua inspiração.

Biembengut $(2014,2016)$ divide o processo de modelar em três fases: percepção $e$ apreensão; compreensão e explicitação; e, significação e expressão:

\section{Percepção e Apreensão}

A primeira parte do processo de Modelagem, conforme Biembengut (2014) é responsável pela percepção das ideias, informações, dados, eventos, para posteriormente Tangram - Revista de Educação Matemática, Dourados - MS - v.2 n.4, pp. 79 - 95 (2019) 


\section{Música e Modelagem Matemática: representações de notas musicais por meio da função seno}

apreendê-los, selecionando e relacionando com o que está sendo proposto. "Na medida em que percebemos, nos familiarizamos com os dados, a situação torna-se mais clara e apreendemos" (Biembengut, 2014, p.24).

Esta etapa é importante, pois se trata do momento em que serão selecionados os autores a serem estudados, seja por meio de livros ou até mesmo em experimentos de especialista no tema escolhido, é necessário também especificar a situação problema, o fenômeno ou o assunto a tratar (BIEMBENGUT, 2016).

Para Biembegut (2014) está fase inclui ações como: reconhecimento da situaçãoproblema; familiarização com o assunto a ser modelado. Fase em que Bassanezi (2010) denomina escolha do tema e coleta de dados.

\section{Compreensão e Explicitação}

Fase que conforme Biembengut (2014) é dividida principalmente na formulação e resolução do modelo. "Baseada em uma compreensão criteriosa da situação-problema ou fenômeno, buscamos propor um sistema conceitual, a fim de explicitar os dados" (Biembengut, 2014, p.24). Isso consiste em classificar informações relevantes, formular pressupostos e hipóteses, identificar variáveis envolvidas e descrever relações em termos matemáticos - modelos.

Biembengut (2014) considera que está fase inclui ações como: formulação do problema, formulação do modelo (matemática), resolução do problema a partir do modelo. Etapas que estão em consonância com Bassanezi (2010).

\section{Significação e Expressão}

Com base nos resultados apresentados na etapa anterior, faz-se nesta fase a interpretação - validação e avaliação desses resultados, verificando sua adequabilidade e o quanto a solução encontrada é significativa e relevante. "Se o modelo atender às necessidades que o geraram, procuramos descrever, deduzir ou verificar outros fenômenos ou deduções - mostrar sua significação" (Biembengut, 2014, p.25).

Caso este modelo não atenda essas necessidades, retorna-se à(s) etapa(s) anterior(es), modificando e/ou alterando hipóteses e variáveis. "Ao finalizar o processo de modelar, é 


\title{
Música e Modelagem Matemática: representações de notas musicais por meio da função seno
}

relevante expressarmos todo o processo a fim de que possa valer a outra pessoa que tenha interesse no assunto ou a nós mesmos" (BIEMBENGUT, 2014, p.25).

Para Biembegut (2014) esta fase inclui ações como: interpretação da solução, validação do modelo - avaliação, expressão dos resultados - modelo. Para Bassanezi (2010), consiste na validação: "processo de aceitação ou não do modelo proposto" (Bassanezi, 2010, p.30). Cabe salientar que essas três fases do processo de modelagem expressos pro Biembengut $(2014,2016)$ não são disjuntas, ou seja, pode-se retornar para qualquer uma das fases anteriores, caso haja necessidade.

Vários pesquisadores defendem a utilização da modelagem na Educação Básica. Conforme Madruga (2016) a modelagem matemática já é uma área consolidada da Educação Matemática, com diversas pesquisas que comprovam sua eficácia no ensino e aprendizagem da disciplina, a mesma, vem sendo utilizada por muitos professores. Para a autora "ainda há certo receio por parte de alguns professores em utilizar a modelagem matemática na Educação Básica, alegando principalmente a insegurança e o - engessamento do currículo, que impossibilitam tal prática" (Madruga, 2016, p. 253). No entanto, Madruga (2016, p. 256), afirma que:

\begin{abstract}
A utilização dos princípios de modelagem mostra-se como uma possibilidade, buscando a formação de sujeitos capazes e sensíveis na identificação e na solução das questões atuais. Além disso, ambientes que proporcionem esses atributos são potenciais espaços para o desenvolvimento da criatividade. Garantir esses espaços em ambientes formais de ensino deve ser tarefa a ser cumprida na composição curricular.
\end{abstract}

Dessa forma, acredita-se que a modelagem pode ser inserida na Educação Básica por meio da criação de modelos que possuam relação com as práticas sociais e culturais dos estudantes. Uma das possíveis relações é entre música e conteúdos matemáticos, visto que a música faz parte da vida de muitas pessoas.

\section{Procedimentos metodológicos}

A pesquisa é de cunho qualitativo, pois visa à descoberta e a busca por novas respostas e indagações no desenvolvimento da pesquisa. Perpassa as características propostas por Bogdan e Biklen (2010): 1) o ambiente natural é a fonte dos dados e o investigador é o Tangram - Revista de Educação Matemática, Dourados - MS - v.2 n.4, pp. 79 - 95 (2019) 


\section{Música e Modelagem Matemática: representações de notas musicais por meio da função seno}

instrumento principal; 2) descritiva; 3) interesse pelo processo; 4) análise de dados de forma indutiva; 5) importância do significado. Na pesquisa qualitativa, o pesquisador interpreta a realidade, observa, registra e analisa interações reais entre pessoas e sistemas.

O desenvolvimento desta pesquisa perpassou as fases da modelagem (matemática) descrita por Biembengut (2014, 2016) em concordância com Bassanezi (2010).

Na fase de percepção e apreensão, ocorreu a escolha do tema: música. Posteriormente, passou-se para a fase de familiarização com o assunto a ser modelado, onde foram efetuadas buscas acerca da temática em questão, e determinado o objetivo da investigação: investigar as relações entre Matemática e música na construção de um modelo de notas musicais. A motivação pela escolha do tema deu-se pelo fato do primeiro autor deste artigo ter estreita relação com a música.

Na fase de compreensão e explicitação, ocorreu a formulação e resolução do modelo. Esta etapa constitui-se na gravação de uma nota musical emitida por instrumento de corda: violão. Para esta gravação, utilizou-se o software Audacityl.3 Beta, para que, por meio do microfone de um notebook, fosse possível gravar o som de uma das cordas do violão para análise das curvas. O programa disponibiliza o recurso de aproximação das ondulações gravadas, recurso este que possibilitou analisar um pequeno trecho de cada registro. A partir disso, foi possível encontrar o período das ondulações neste pequeno trecho. Em seguida, construindo o modelo que apresentou características de uma senóide.

$\mathrm{Na}$ fase de significação e expressão, este modelo foi validado por meio do software Geogebra, no qual foi possível reproduzir a função sen(x), configurando os comandos para diferentes intervalos de tempo, lançando valores que multiplicam o " $\mathrm{x}$ " [da função sen(x)], para que as ondulações tornem-se cada vez mais juntas até encontrar as ondulações por tempo (ou frequência) necessárias.

\section{Resultados e discussão - desenvolvimento do modelo}

A nota escolhida para ser analisada nesta pesquisa foi a " $R \hat{e}$ ", som emitido pela quarta corda do violão quando afinado à diapasão de forma convencional. É importante ressaltar que o software foi utilizado para fazer as gravações, ao registrar as ondas sonoras, foi possível perceber o aspecto decrescente no decorrer do tempo, um tanto desregular referente

Tangram - Revista de Educação Matemática, Dourados - MS - v.2 n.4, pp. 79 - 95 (2019) 


\section{Música e Modelagem Matemática: representações de notas musicais por meio da função seno}

à perda de energia da onda ao se propagar na corda do violão. Assim como a amplitude da onda está diretamente relacionada com a força a qual a corda é tocada, e a proximidade do violão ao microfone.

\section{Percepção e Apreensão}

Fase onde foram realizadas as primeiras buscas e estudos sobre o tema. A busca por subsídios foi realizada em obras que tratam de música, notas musicais e violão, instrumento de preferência do autor da pesquisa.

O manuseio do software Audacity foi um dos principais fatores de motivação para esse trabalho. Ao fazer gravações de músicas com voz e violão, o autor percebeu as ondulações de forma muito aproximadas no visor de faixa de gravação, de tanto utilizar o programa para a mesma finalidade, percebeu um recurso capaz de ampliar a imagem do visor no sentido horizontal, quanto mais ampliava a imagem as ondulações tomavam formas mais bem definidas dando a perceber que se tratara de uma função.

\section{Compreensão e Explicitação}

Esta consiste na fase em que o modelo foi efetivamente construído. A seguir, são explicitados os passos utilizados para elaboração do mesmo.

\section{- Gravação e análise}

A escala de "Ré" é composta pelas seguintes notas:

$$
1^{\mathrm{a}} \text { Ré - } 2^{\mathrm{a}} \mathrm{Mi}-3^{\mathrm{a}} \text { Fá\# - } 4^{\mathrm{a}} \mathrm{Sol}-5^{\mathrm{a}} \text { Lá - } 6^{\mathrm{a}} \mathrm{Si}-7^{\mathrm{a}} \text { Dó\# - } 8^{\mathrm{a}} \text { Ré (oitava) }
$$

\section{- Situação I}

A partir do som emitido pela quarta corda de um violão de náilon (nota $R e ́$ ), gravado pelo software Audacity 1.3 Beta, com uma aproximação do gráfico produzido pelo som projetado no software, possibilita a visualização da forma da onda. É importante ressaltar que esta aproximação feita pelo software é aplicada apenas na horizontal, ou seja, na vertical a imagem permanece a mesma, para que o registro possa ser analisado com êxito.

Tangram - Revista de Educação Matemática, Dourados - MS - v.2 n.4, pp. 79 - 95 (2019) 


\section{Música e Modelagem Matemática: representações de notas musicais por meio da função seno}

Como é possível identificar na Figura 1, foi selecionado o intervalo de tempo entre 0,1 e 0,2 segundo, então, foi identificado um pouco mais do que quatorze ondulações e meia. Fazendo o cálculo da frequência, ao dividir o número de ondulações (aproximadamente $14,8 \lambda)$ pela diferença entre o tempo final e o tempo inicial considerado $(0,2 \mathrm{~s}-0,1 \mathrm{~s}=0,1 \mathrm{~s})$, em seguida, ao dividir ambos pela diferença do tempo novamente, para que de fato independente do tempo obtido, o valor do denominador seja um segundo (1s), uma vez que $1 \lambda / 1 \mathrm{~s}=1 \mathrm{~Hz}: 14,8 \lambda /(0,2 \mathrm{~s}-0,1 \mathrm{~s})=14,8 \lambda / 0,1 \mathrm{~s}=(14,8 \lambda / 0,1 \mathrm{~s}) /(0,1 \mathrm{~s} / 0,1 \mathrm{~s})=148 \lambda / \mathrm{s}=148 \mathrm{~Hz}$, ou seja, o valor aproximado da frequência da nota Ré.

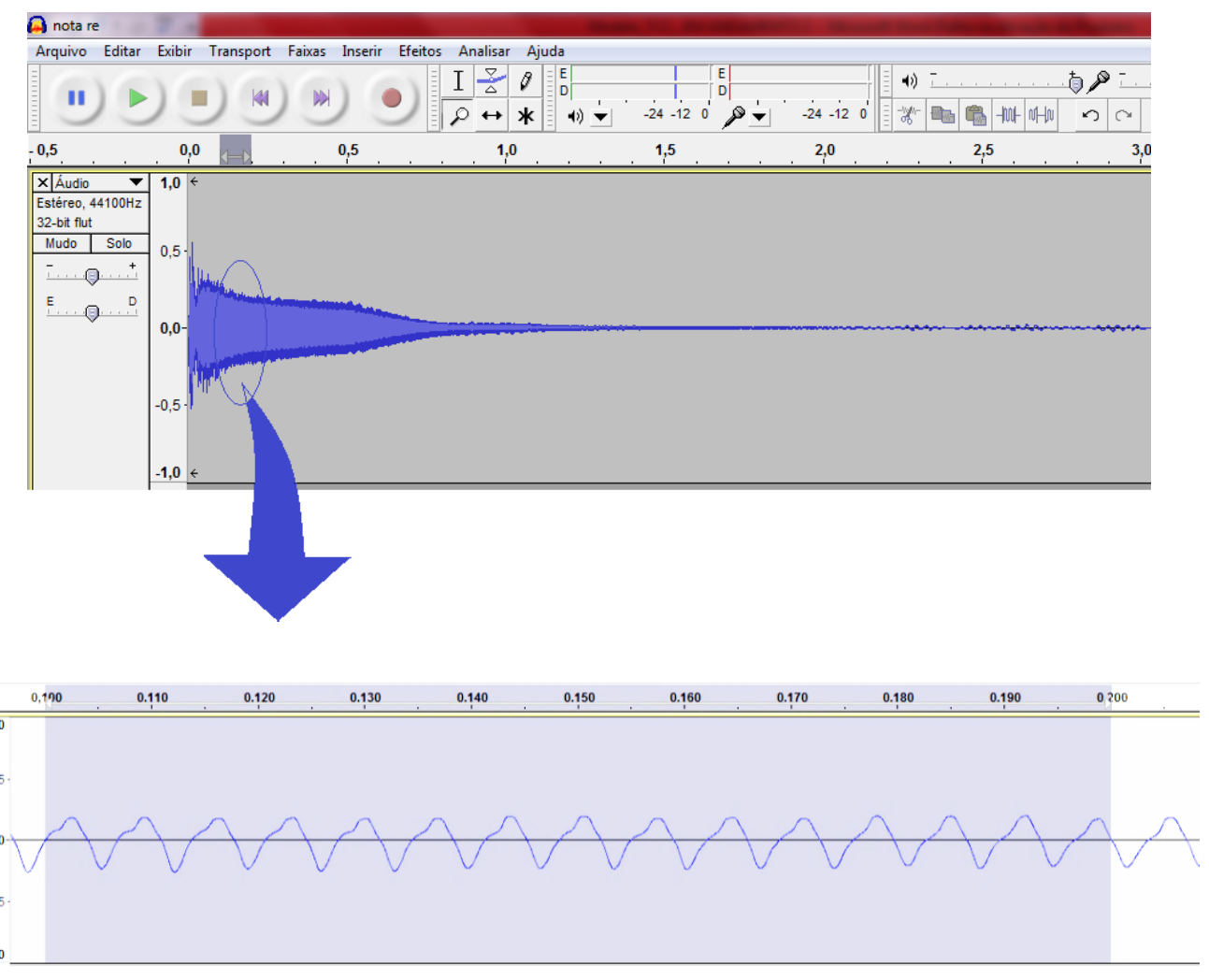

Figura 1 - Software Audacity - Gravação da Nota Ré (148 Hz)

Fonte: Os autores (2019).

- Situação II

Em seguida, ao pressionar a mesma corda na décima segunda casa (casa que divide a corda pela metade) o que corresponde também à nota Ré, mas desta vez como a oitava nota da escala de Ré, e gravando o som no mesmo software para então comparar com o gráfico Tangram - Revista de Educação Matemática, Dourados - MS - v.2 n.4, pp. 79 - 95 (2019) 


\section{Música e Modelagem Matemática: representações de notas musicais por meio da função seno}

anterior no mesmo intervalo de tempo. Daí, ao somar um pouco mais do que vinte e nove ondulações e meia $(29,6 \lambda)$, desta forma, o próximo passo é calcular:

$29,6 \lambda / 0,1 \mathrm{~s}=(29,6 \lambda / 0,1 \mathrm{~s}) /(0,1 \mathrm{~s} / 0,1 \mathrm{~s})=296 \lambda / 1 \mathrm{~s}=296 \mathrm{~Hz}$ (Figura 2$).$

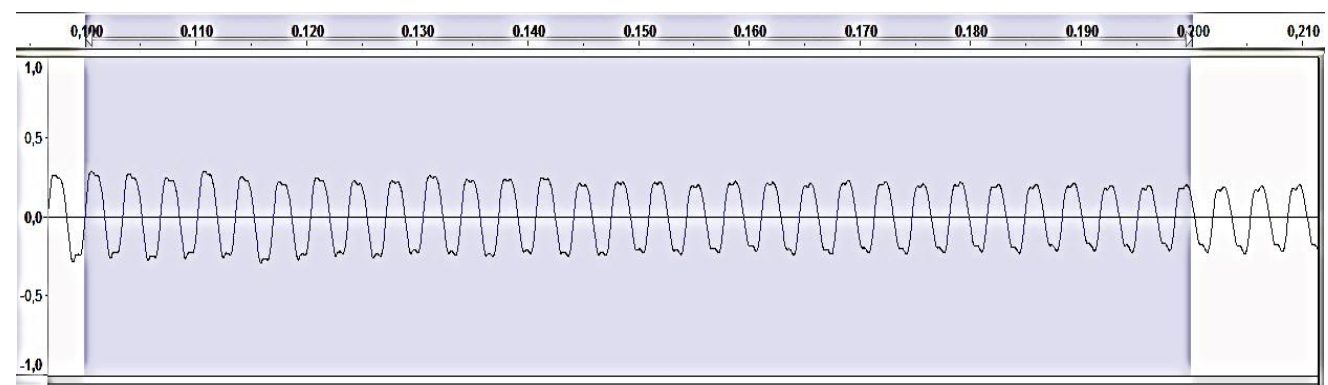

Figura 2 - Software Audacity - Gravação da Nota Ré oitavada (296 Hz) Fonte: Os autores (2019).

- Situação III

Posteriormente, ao captar o som emitido pela quarta corda novamente, desta vez, pressionando a corda na sétima casa (casa que divide a corda em 2/3), é possível contar pouco mais do que vinte e duas ondulações (aproximadamente $22,2 \lambda$ ) no instante de $0,1 \mathrm{~s}$ a 0,2s, ou seja, uma frequência de $222 \mathrm{~Hz}$ correspondendo à nota Lá (Figura 3).

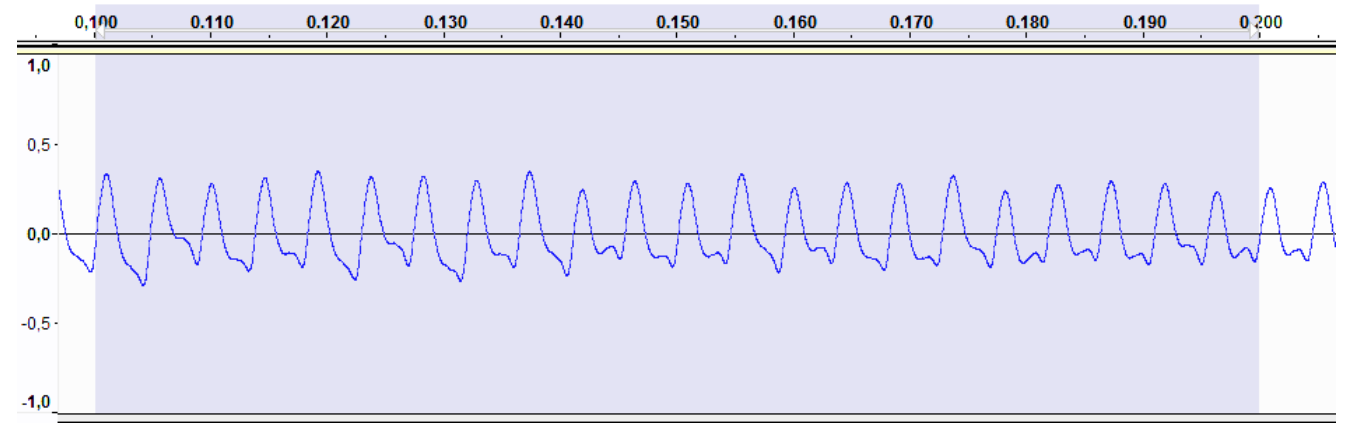

Figura 3 - Software Audacity - Gravação da Nota Lá (222 Hz)

Fonte: Os autores (2019).

Tangram - Revista de Educação Matemática, Dourados - MS - v.2 n.4, pp. 79 - 95 (2019) 


\section{Música e Modelagem Matemática: representações de notas musicais por meio da função seno}

\section{- Situação IV}

Captando o som da quarta corda tocada com o dedo pressionado na quinta casa (casa que isola 1/4 da corda do violão), estão presentes mais do que dezenove ondulações e meia no instante de 0,1s a 0,2s. Obtendo assim, a frequência de $197 \mathrm{~Hz}$ o que corresponde à nota Sol (Figura 4).

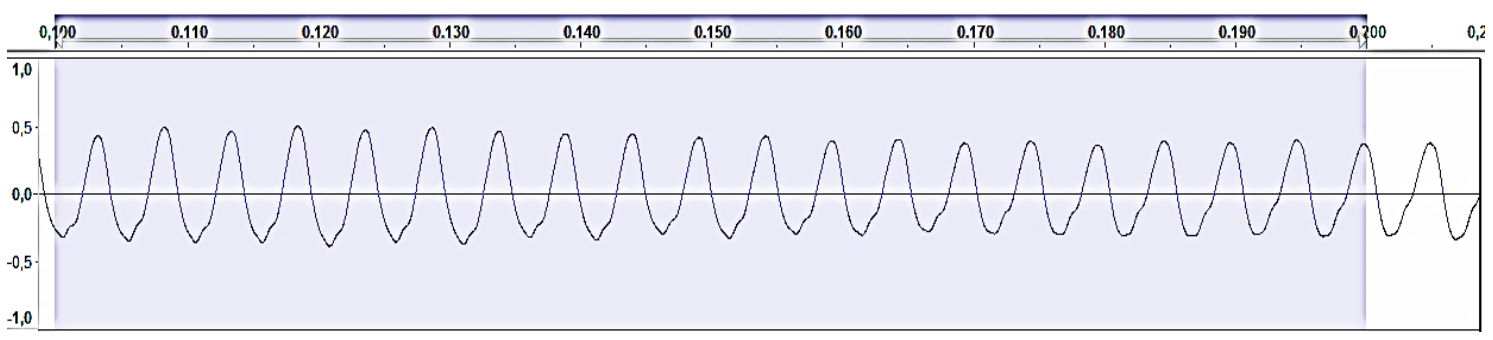

Figura 4 - Software Audacity - Gravação da Nota Sol (197 Hz) Fonte: Os autores (2019).

- Análise I: Entre as situações I e II

Ao tocar a quarta corda solta (situação) foi obtida $148 \mathrm{~Hz}$ de frequência, e quando a mesmo corda é tocada pressionando-a contra a décima segunda casa foi registrado uma frequência de $296 \mathrm{~Hz}$, ou seja, o dobro da frequência, dessa forma foi estabelecida uma relação de aproximadamente 1 para 2 , ou 1/2.

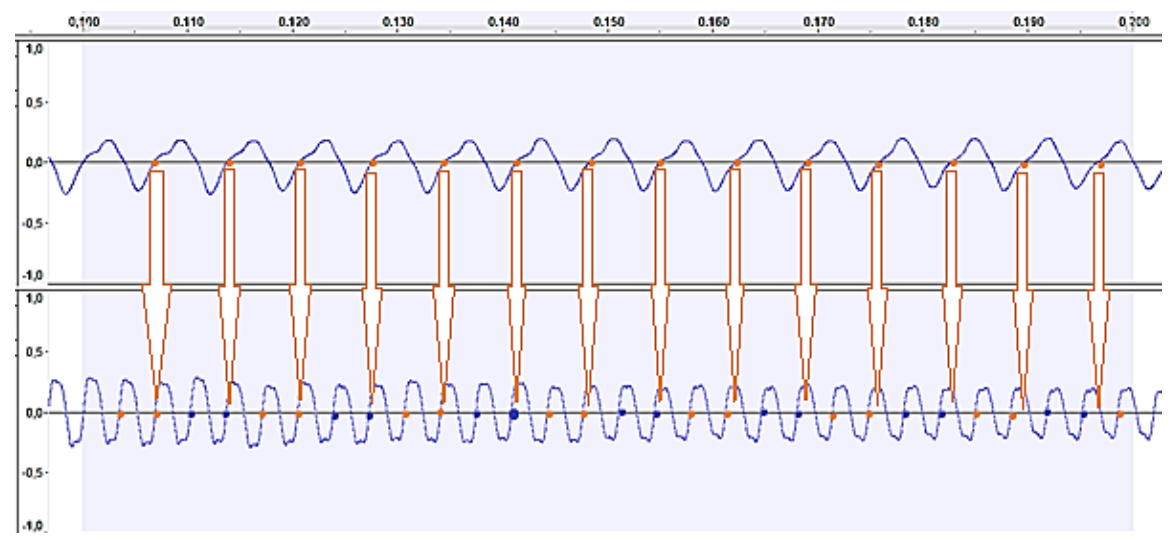

Figura 5 - Software Audacity - Gravação das Notas Ré e Ré oitavada Fonte: Os autores (2019). 


\section{Música e Modelagem Matemática: representações de notas musicais por meio da função seno}

- Análise II: Entre as situações I e III

Ao tocar a quarta corda solta (situação), foi obtida, $148 \mathrm{~Hz}$ de frequência, e quando a mesma corda é tocada pressionando-a contra a sétima casa foi considerada uma frequência de $222 \mathrm{~Hz}$, o que reflete em uma relação de 2 para 3, ou 2/3.

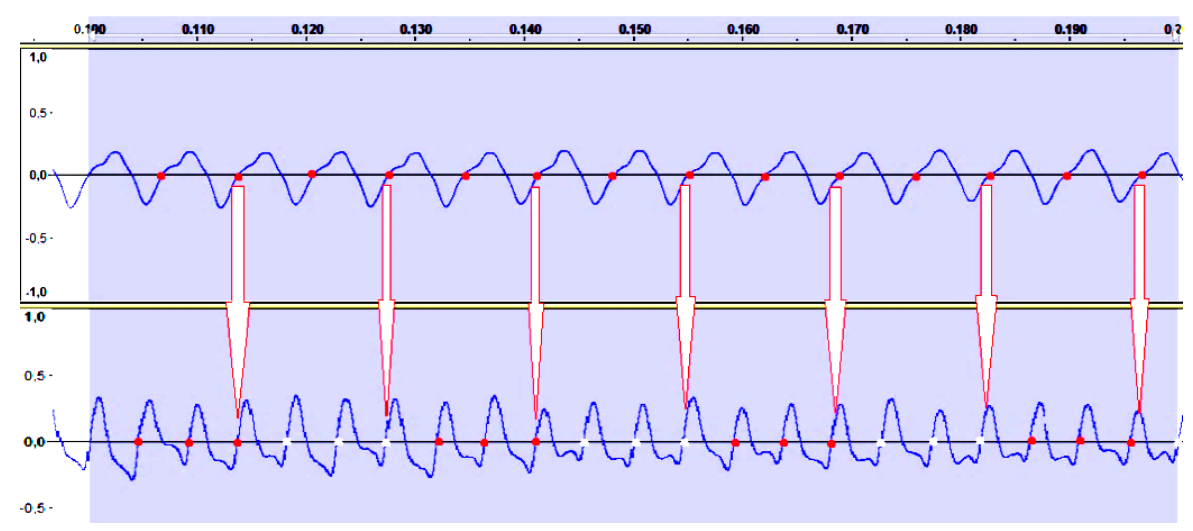

Figura 6 - Software Audacity - Gravação das Notas Ré e Lá Fonte: Os autores (2019).

- Análise III: Entre as situações I e IV

Ao tocar a quarta corda solta (situação) obteve-se $148 \mathrm{~Hz}$ de frequência, e quando a mesmo corda é tocada pressionando-a contra a quinta casa, a frequência obtida foi de 195 $\mathrm{Hz}$, dessa forma, é estabelecida uma relação de aproximadamente 3 para 4, ou 3/4.

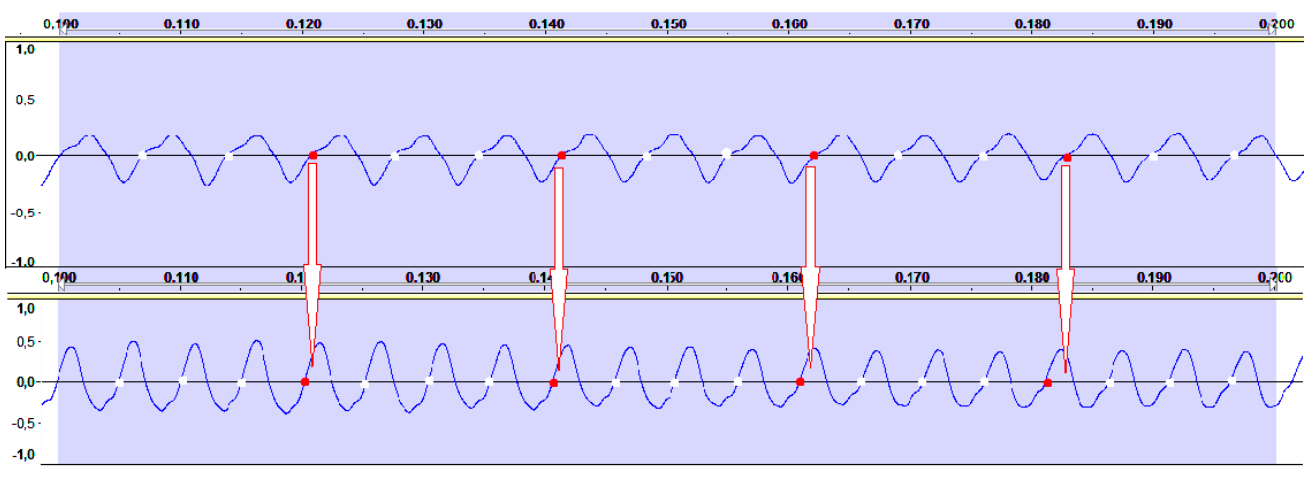

Figura 7 - Software Audacity - Gravação das Notas Ré e Sol Fonte: Os autores (2019).

Tangram - Revista de Educação Matemática, Dourados - MS - v.2 n.4, pp. 79 - 95 (2019) 


\section{Música e Modelagem Matemática: representações de notas musicais por meio da função seno}

\section{Significação e Expressão}

Nesta etapa procurou-se validar o modelo por meio do software Geogebra pela sua funcionalidade capaz de reproduzir o gráfico de uma função qualquer apenas digitando a função em um campo de entrada do sistema.

\section{- Validação do modelo por meio do Geogebra}

Como é possível perceber, o registro da nota Ré tem um comportamento semelhante ao da função seno. Desta forma, foi utilizado o software Geogebra para se obter o modelo desejado.

Para encontrar a função que representa a nota Ré, o "eixo x" foi considerado como tempo medido em segundos (s). Lançando a função trigonométrica " $\mathrm{f}(\mathrm{x})=\operatorname{sen}(\mathrm{x})$ " no campo "Entrada" do Geogebra, sabe-se que um ciclo da função seno equivale a $2 \pi=2 \times 3,14=6,28$ (considerando $\pi=3,14$ ). Daí, a frequência desta curva equivale a1 $\lambda / 6,28 \mathrm{~s}=0,1592 \lambda / \mathrm{s}=$ $0,1592 \mathrm{~Hz}$ (aproximado na quarta casa decimal), gráfico da função na figura 8 .

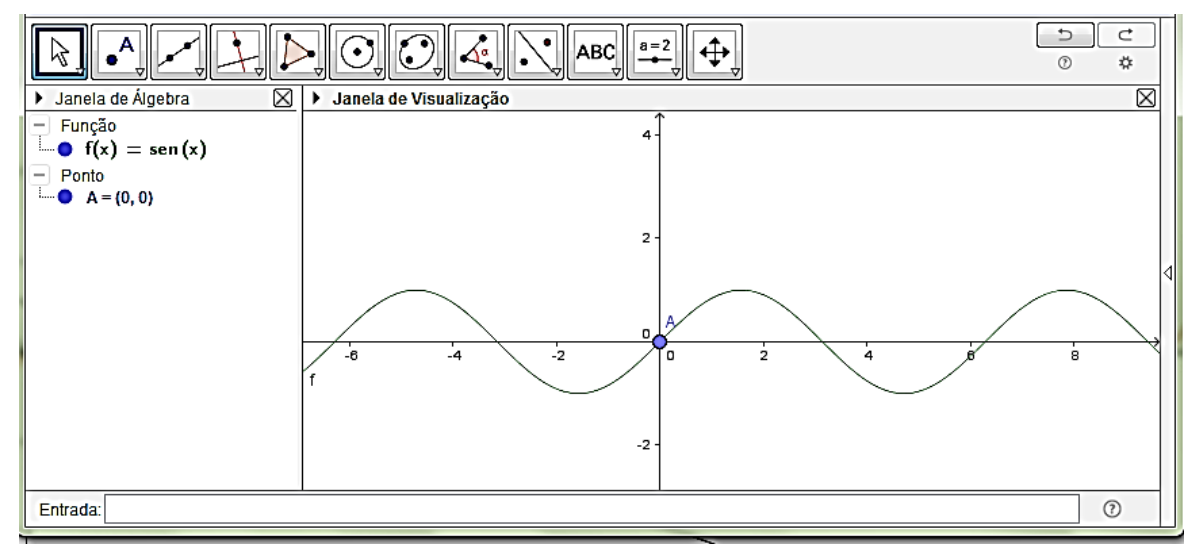

Figura 8 - Software Geogebra - Função $\mathrm{f}(\mathrm{x})=\operatorname{sen}(\mathrm{x})$

Fonte: Os autores (2019).

Assumindo que " $\mathrm{g}(\mathrm{x})=\operatorname{sen}(\mathrm{ax})$ " é a função que irá representar a nota $R e$, é possível afirmar que a frequência de $g$ é diretamente proporcional a "a", e que:

Frequência de $\operatorname{sen}(x)=\operatorname{sen}(1 x)$, equivale a $0,1592 \mathrm{~Hz}$.

Frequência da nota $R e ́(\mathrm{~g}(\mathrm{x})=\operatorname{sen}(\mathrm{ax}))$, equivale a $148,104 \mathrm{~Hz}$ (desta vez, foram utilizadas três casas decimais para obter resultados mais precisos). Desta forma:

Tangram - Revista de Educação Matemática, Dourados - MS - v.2 n.4, pp. 79 - 95 (2019) 


\section{Música e Modelagem Matemática: representações de notas musicais por meio da função seno}

$$
\begin{aligned}
& 1 / a=0,1592 \mathrm{~Hz} / 148,104 \mathrm{~Hz} \\
& a=148,104 \mathrm{~Hz} / 0,1592 \mathrm{~Hz} \\
& a=930,3
\end{aligned}
$$

Logo, $g(x)=\operatorname{sen}(930,3 x)$ é a função que pode representar a nota Ré.

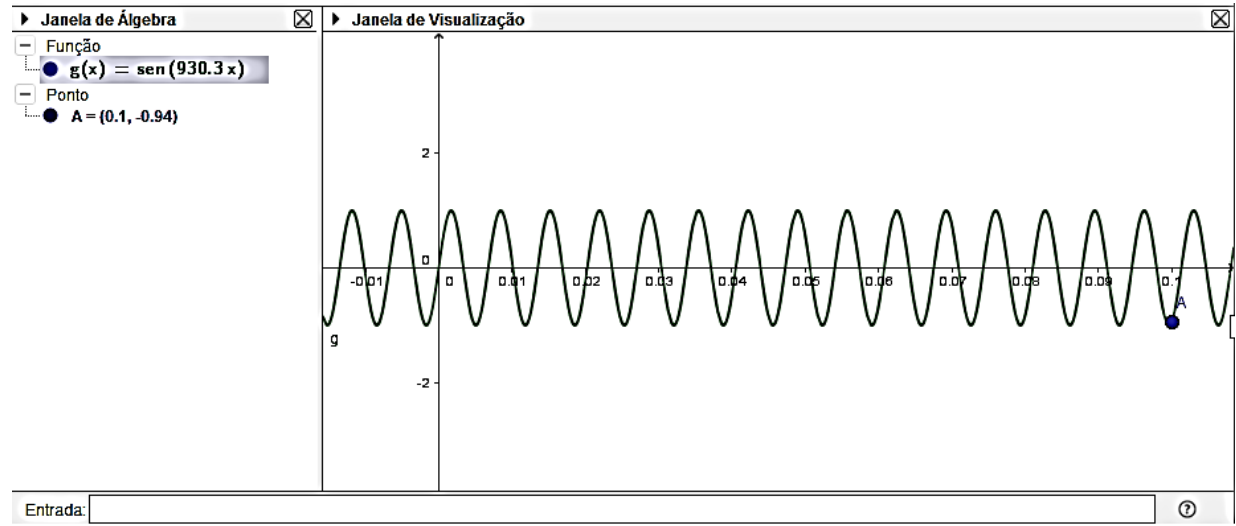

Figura 9 - Software Geogebra - Função $\mathrm{g}(\mathrm{x})=\operatorname{sen}(930,3 \mathrm{x})$

Fonte: Os autores (2019).

Desta forma, é possível identificar a função (h) para qualquer nota musical com a imagem variando de -1 até 1 a partir da sua respectiva frequência (fr) da seguinte forma: $\mathrm{H}(\mathrm{x})=\operatorname{sen}[(\mathrm{fr} / 0,1592 \mathrm{~Hz}) \mathrm{x}]$.

\section{- Análise geral das gravações}

Ao tocar a quinta corda do violão pressionada contra a quinta casa, a nota obtida também será a Ré. Tocando-a simultaneamente com qualquer uma das notas acima, será obtido um som agradável e harmônico. Desta forma, ao tocar simultaneamente a quinta corda pressionada na quinta casa e a quarta corda solta, a frequência obtida será a mesma, desta forma, uma relação de 1 para 1 ou 1/1, o som será praticamente igual. Nas três análises acima, foram obtidas as respectivas relações entre as notas: 1/2 , 2/3 e 3/4. Nas Análises I, II e III é possível encontrar estas relações dividindo uma frequência pela outra e fatorar até encontrar os números primos entre si. Por exemplo: 


\section{Música e Modelagem Matemática: representações de notas musicais por meio da função seno}

$$
(148 \mathrm{~Hz}) /(222 \mathrm{~Hz})=(148 \mathrm{~Hz} / 2) /(222 \mathrm{~Hz} / 2)=(74 \mathrm{~Hz} / 111 \mathrm{~Hz})=(74 \mathrm{~Hz} / 37) /(111 \mathrm{~Hz} / 37)=
$$

$2 \mathrm{~Hz} / 3 \mathrm{~Hz}=2 / 3$

Ao tocar simultaneamente a nota Ré $(148 \mathrm{~Hz})$ juntamente com uma nota fora da sua escala, como por exemplo, a nota Fá que possui a frequência de aproximadamente $176 \mathrm{~Hz}$ e buscar uma relação dividindo a frequência menor pela maior, encontra-se :

$148 \mathrm{~Hz} / 176 \mathrm{~Hz}=148 / 176=(148 / 4) /(176 / 4)=37 / 44$

Ou seja, (lembrando que estão sendo considerados valores aproximados) é confortável uma representação comparando que 37 ondulações do som emitido pelo violão na nota Ré, equivalem a 44 ondulações do mesmo referente à nota Fá. Na música, quando maior for o valor desses números primos entre si, maior será o desconforto para quem ouve esses sons tocados ao mesmo tempo, representando uma dissonância.

Pelo exposto, pode-se perceber que é possível estabelecer uma relação entre a Matemática e a Música (inteligência lógico-matemática e inteligência musical), utilizando a modelagem matemática como método de pesquisa aplicado à Educação. Nesta pesquisa, criou-se um modelo de uma nota musical que resultou em uma função trigonométrica: função seno, e a partir desta proposta, pode refletir sobre as diversas possibilidades de relações que podem ser inseridas nas aulas de Matemática.

\section{Considerações finais}

Esta pesquisa teve como objetivo construir um modelo, utilizando notas musicais, que possa ser aplicado no ensino de matemática. Para isso, tomou-se como base teórica os pressupostos da modelagem matemática. Após a busca por fundamentar a pesquisa, foram feitas gravações de algumas notas musicais (todas de uma mesma escala - Ré) de um violão, para a análise do comportamento e das suas respectivas frequências e a explicação matemática para o fato de apresentarem harmonia entre si. Em seguida, por meio do software Geogebra, foi encontrada uma função que representa a principal nota musical estudada nesta pesquisa, e uma forma para encontrar a representação de uma nota musical com uma função trigonométrica por meio da sua frequência.

Um dos fatores importante foi à aplicação da função trigonométrica seno de uma forma que não é trabalhada usualmente em sala de aula, e que pode ser usada como exemplo Tangram - Revista de Educação Matemática, Dourados - MS - v.2 n.4, pp. 79 - 95 (2019) 


\section{Música e Modelagem Matemática: representações de notas musicais por meio da função seno}

na introdução do assunto para que o estudante perceba, por meio da modelagem, em que área pode ser visto e aplicado o conhecimento que ele estará adquirindo. Dessa forma, o estudante pode sentir-se motivado para a aprendizagem de Matemática, e percebê-la em seu cotidiano.

Ao interpretar e avaliar os resultados desta pesquisa destaca-se que a utilização da modelagem matemática em sala de aula pode instigar os estudantes a levantar hipóteses, observar, refletir, interpretar, solucionar problemas e perceber na música, conteúdos de Matemática que podem ser aprendidos e significados.

O exemplo exposto nessa pesquisa sugere a utilização da modelagem matemática para auxiliar no ensino e na aprendizagem de conteúdos matemáticos (função seno). E, ainda, potencializar o desenvolvimento das inteligências lógico-matemática e musical nos estudantes, por meio da valorização da música, a qual faz parte da vida de várias pessoas. Como perspectiva de continuidade deste estudo, tem-se a intenção de aplicar esta prática em turmas de Ensino Médio da Educação Básica, para validar a proposta e aprimorá-la por meio de novas investigações.

\section{Referências}

Abdounur, Oscar João. (2003). Matemática e Música: pensamento analógico na construção de significados. São Paulo: Escrituras Editora.

Bassanezi, Rodney Carlos. (2010). Ensino-aprendizagem com Modelagem Matemática. São Paulo: Contexto.

Bogdan, Robert \& Biklen, Sari. (2010). Investigação Qualitativa em Educação. Porto, Portugal: Editora Porto.

Biembengut, Maria Salett. (2014). Modelagem Matemática no Ensino Fundamental. $1^{\text {a }}$ Ed. São Paulo: EDIFURB.

Biembengut, Maria Salett. (2016). Modelagem na Educação Matemática e na Ciência. São Paulo: Editora Livraria da Física.

Brasil. (2018). Base Nacional Comum Curricular. Disponível em $<$ http://basenacionalcomum.mec.gov.br/wpcontent/uploads/2018/04/BNCC_EnsinoMedio_embaixa_site.pdf $>$ Acesso em 15 de outubro de 2018.

Tangram - Revista de Educação Matemática, Dourados - MS - v.2 n.4, pp. 79 - 95 (2019) 
Música e Modelagem Matemática: representações de notas musicais por meio da função seno

Brasil. (2013). Diretrizes Curriculares Nacionais da Educação Básica. Ministério da Educação. Secretaria de Educação Básica. Diretoria de Currículo e Educação Integral. Brasília - DF: MEC, SEB, DICEI, 562 p.

Brasil. (1996). LDB: Lei de Diretrizes e Bases da Educação Nacional. Lei no 9.394, de 20 de dezembro de 1996, que estabelece as diretrizes e bases da educação nacional. 9. ed. - Brasília: Câmara dos Deputados, Edições Câmara.

Camargos, Chrislei Bruno Ribeiro (2010). Música e Matemática: a harmonia dos números revelada em uma estratégia de modelagem. Dissertação de Mestrado. Universidade Federal de Ouro Preto, Ouro Preto, MG.

Gardner, Howard. (1994). Estruturas da Mente: A Teoria das Inteligências Múltiplas. Trad. Sandra Costa. Porto Alegre, RS: Artes Médicas Sul.

Gardner, Howard. (1995). Inteligências Múltiplas: a teoria na prática. Trad. Maria Adriana Veríssimo Veronese. Porto Alegre, RS: Artes Médicas Sul.

Grams, Ana Laura Bertelli. (2014). Modelagem Matemática no Ensino Médio: Percepção matemática por meio da música. Dissertação de Mestrado. Pontifícia Universidade Católica do Rio Grande do Sul, Porto Alegre, RS.

Madruga, Zulma Elizabete de Freitas. (2016). Processos criativos e valorização da cultura: possibilidades de aprender com modelagem. Tese de Doutorado. Pontifícia Universidade Católica do Rio Grande do Sul, Porto Alegre, RS.

Enviado:08/08/2019 Aceito:14/10/2019

Tangram - Revista de Educação Matemática, Dourados - MS - v.2 n.4, pp. 79 - 95 (2019) 